\title{
Applications of cone beam computed tomography in endodontics
}

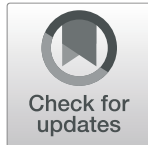

Ateksha Bhardwaj Khanna ${ }^{1,2,3,4}$ (D)

\begin{abstract}
Endodontic disease can adversely affect the quality of life and therefore early diagnosis and consequent timely treatment is of paramount importance for the Endodontist. Radiology is an essential component in treatment planning, disease monitoring and assessment of treatment outcome. Periapical radiographs and panoramic radiography are frequently utilised but they provide only two-dimensional representation of three-dimensional structures. The advent of cone beam computed tomography (CBCT) offers three-dimensional accuracy of the hard tissue images with a reasonable cost and this has revolutionised imaging of the dentomaxillofacial structures. This imaging system has been seen to overcome some limitations of conventional radiography, as brought out in this review. The improvement in the accuracy is, however, accompanied at the cost of increased radiation exposure to the patient. Nevertheless, smaller areas of exposure are normally appropriate for endodontic imaging, and adjustment in the exposure parameters can further moderate the effective dose (Loubele et al. 37(6):309-18, 2008).

Aims and objectives: The aim of this review is to present the pertinent literature on the various applications of cone beam computed tomography in the field of endodontics.

Methods: Literature was electronically searched on the following sources; Medline and Keats Library. Further, a manual search was performed on the following journals: International Endodontic Journal, Journal of Endodontics, Oral Surgery, Oral Medicine, Oral Pathology, Oral Radiology, Endodontology, Journal of Dental Research, European Journal of Oral Sciences \& Odontology and Dentomaxillofacial Radiology. A preliminary search was performed to gain an idea of the available literature using keywords 'Cone Beam Computed Tomography' to view the volume of the literature evident and identify questions to be addressed in this review. The initial search showed 243 potential articles. After scrutinising the titles and abstracts of the retrieved articles, 70 relevant studies were reviewed in full text. Furthermore, 'published guidelines on the use of $\mathrm{CBCT}^{\prime}$ were also searched so as to include the results as an additional source material. All the articles eligible to be included in the review were in the English language and ranged from the year 1960 to the present. Also all the studies reviewed were based on the various uses of cone beam computed tomography in the field of endodontics. The keywords used to search were 'Cone Beam Computed Tomography (CBCT)', 'Conventional radiography', 'Applications of CBCT in endodontics', 'CBCT and tooth morphology', 'CBCT and apical periodontitis', 'CBCT and vertical root fractures', 'CBCT and resorption', 'CBCT and pre-surgical assessment', 'CBCT and dento-alveolar trauma' and 'CBCT and endodontic outcome'.

(Continued on next page)
\end{abstract}

Correspondence: dratekshakhanna@gmail.com

${ }^{1}$ Royal College of Surgeons of England, London, UK

${ }^{2}$ Royal College of Surgeons of Edinburgh, Edinburgh, UK

Full list of author information is available at the end of the article

(c) The Author(s). 2020 Open Access This article is licensed under a Creative Commons Attribution 4.0 International License, which permits use, sharing, adaptation, distribution and reproduction in any medium or format, as long as you give appropriate credit to the original author(s) and the source, provide a link to the Creative Commons licence, and indicate if changes were made. The images or other third party material in this article are included in the article's Creative Commons licence, unless indicated otherwise in a credit line to the material. If material is not included in the article's Creative Commons licence and your intended use is not permitted by statutory regulation or exceeds the permitted use, you will need to obtain permission directly from the copyright holder. To view a copy of this licence, visit http://creativecommons.org/licenses/by/4.0/. 
(Continued from previous page)

Results: Every case is unique and CBCT should be considered only after studying each case individually. CBCT imaging needs to be adopted or used where information from conventional imaging systems is either inadequate for the management of endodontic problems or inconclusive. Having said that, it is safe to state that CBCT imaging has the potential to become the first choice for endodontic treatment planning and outcome assessment, especially when new scanners with lower radiation doses and enhanced resolution would be available.

\section{Introduction}

Radiographic assessment is a fundamental component in the management of endodontic problems (Patel \& Dawood, 2007a). Endodontic diagnosis, management and outcome assessment are still very much dependent on conventional radiography (European Society of Endodontology, 2006; Glickman, 2006).

With digital technological advances in the various imaging systems used across the medical fraternity, cone beam computed tomography has emerged as an invaluable tool. The development of CBCT has highlighted the inadequacies of conventional radiography which are compression of a three-dimensional anatomy, geometric distortion and anatomical noise (Durack et al., 2011). Needless to state, clinicians should have a thorough knowledge on CBCT before prescribing/using it for the patients. It comes as a natural corollary that clinicians should first and foremost carefully analyse whether a CBCT scan would have net benefit in the management of the patient's problem before venturing further (IRME R, 2000; Patel \& Horner, 2009; Holroyd \& Gulson, 2010). Furthermore, clinicians should ensure that every radiation exposure is justified and kept as low as reasonably practicable (ICRP, 2007).

\section{Periapical radiography-indications and limitations}

Common indications of periapical radiography in endodontics are diagnosis, treatment planning of endodontic and re-endodontic conditions, prior to surgical procedures and assessment of treatment performed.

\section{Limitations of conventional radiography}

Images that are captured using periapical radiography have the following limitations.

Compression of three-dimensional anatomy By compressing the three-dimensional anatomy into a twodimensional image, conventional radiography adversely limits the diagnostic accuracy (Webber \& Messura, 1999; Nance et al., 2000; Cohenca et al., 2007a). The appreciation of the bucco-lingual plane is minimal and the spatial relationship of the roots to the neighbouring anatomical structures is unclear thereby compromising radiographic interpretation.

This missing third-dimension capability is crucial for pre-surgical assessment (Kobayashi et al., 2004; Low et al., 2008a). To find the missing piece of information, parallax radiography is suggested (Matherne et al., 2008a). However, even after multiple exposures, some areas can go undetected (Matherne et al., 2008a; Barton et al., 2003).

Geometric distortion The complexity of the maxillofacial skeleton structure can sometimes obscure radiographic replication (Grondahl \& Huumonen, 2004). For an accurate image, the image receptor should be placed parallel to the long axis of the tooth and the $\mathrm{x}$-ray beam should be perpendicular to the receptor and the tooth being radiographed. A shallow palate, divergent/convergent roots, small mouth or gagging can also disturb the long-axis orientation leading to geometric distortion. Even in ideal conditions, some magnification is inevitable (Whaites, 2007).

Anatomical/structured/background noise Some anatomical features can obstruct the area of interest compromising visualisation. Some common examples are zygomatic buttress, incisive canal and maxillary sinus (Revesz et al., 1974; Gröndahl \& Huumonen, 2004; Kundel \& Revesz, 1976). These can be radio-opaque or radiolucent in nature. The increase in the anatomical noise makes diagnosis even more challenging.

Studies have shown that the disagreements between clinicians occurs when examining periapical lesions in the posterior quadrants (Goldman et al., 1972).

\section{Temporal perspective}

Comparisons between sequential radiographs can assist a clinician to assess the outcome of the treatment performed. However, according to some authors, images captured using periapical radiography can never be reproduced.

\section{Ideal features of an imaging system}

Ideal features of an imaging system are geometric accuracy, minimal superimposition, ease of availability and usage, reliable, reproducible, relatively inexpensive, and most importantly minimum radiation exposure to the patient. 


\section{Cone beam computed tomography—background}

Cone beam computed tomography is an imaging system which was developed in the 1990s. It is used to produce three-dimensional scans of the maxillofacial skeleton at a considerably lower dose as compared to conventional computed tomography (CT) (Mozzo et al., 1998).

CBCT consists of an X-ray source, a detector or sensor which is mounted on a rotating gantry. The X-ray source and reciprocal scanner synchronously rotate around the patients head and acquire a threedimensional volume of data. During the imaging process, the X-ray beam from the source is directed through the area of interest. After passing through the area of interest, the beam is projected into the detector where they both rotate around the patients head in $180^{\circ-} 360^{\circ}$ in a single sweep.

The cone-shaped X-ray beam captures a cylindrical or spherical volume of data which is known as the field of view (FOV). The FOV determines the scan volume and the anatomical area of choice. The smaller the field of view, the lower the dose. Scan times are 10-40 s depending on the scanner used and exposure parameters. Images reconstructed from CBCT can be viewed in three orthogonal planes thereby giving the clinician a three-dimensional view of the desired area. CBCT radiation depends on several factors such as the size of the FOV, continuous or pulsatile nature of the X-ray beam, the exposure parameters $(\mathrm{mA}, \mathrm{kV}$ and scanning time), voxel size and beam filtration. Limited volume CBCT scanners can be used to expose one to two teeth. Depending on the area being scanned by the 3D Accuitomo, the effective dose varies from 13 to $44 \mu \mathrm{Sv}$ (Loubele et al., 2009).

Some studies have verified the linear and volumetric accuracy of CBCT using an acrylic block and human mandible with osseous defects, concluding that $\mathrm{CBCT}$ is a desirable imaging tool for providing additional information for diagnosis and management of complex endodontic problems (Kobayashi et al., 2004; Murmulla et al., 2005).

\section{Classification of cone beam computed tomography (Durack \& Patel, 2012)}

According to field of view or scan volume, the classification of cone beam computed tomography is as follows:

1. Small volume/limited field or limited volume. This has a volume height of $5 \mathrm{~mm}$.

2. Single arch. This has a field of view of $5-7 \mathrm{~cm}$.

3. Inter-arch has a field of view of $7-10 \mathrm{~cm}$.

4. Maxillofacial CBCT has a field of view of $10-15 \mathrm{~cm}$.

5. Cranio-facial CBCT has a field of view height of $15 \mathrm{~cm}$.
A less common system of classifying CBCT is based on the patient positioning (supine, sitting or standing). A large volume CT scanner can capture the entire maxillofacial skeleton. Some examples are $\mathrm{i}^{-\mathrm{CAT}^{\circ}}$ and NewTom 3G. Small volume scanners have a field of view of $40 \mathrm{~mm}$ (height) by $40 \mathrm{~mm}$ (diameter) almost the same height and width of a periapical radiograph (3D Accuitomo ${ }^{\circ}$.

\section{Effective dose of cone beam computed tomography}

Radiation dose of CBCT is dependent on the following exposure parameters:

1. Nature of the X-ray beam (pulsatile or continuous).

2. Amount of rotation of the X-ray source and detector.

3. Size of the field of view. This may vary from few $\mathrm{mm}$ to a complete maxillofacial skeleton scan. There are CBCT units that offer the full range. Some units provide only a fixed field of view. Generally, the field of view is linked to the amount of radiation dose which is further dependent on individual cases. It has been seen that CBCT equipment with large fixed field of view was not appropriate for diagnostic tasks that were localised to cover a few teeth.

4. The type and amount of beam filtration.

5. $\mathrm{kV}, \mathrm{mA}$ and voxel size.

Voxel size or the element by volume is generally a three-dimensional representation. Field of view comprises of a number of voxels. In the CBCT equipment, the size of the voxel varies from 0.1 to $0.4 \mathrm{~mm}$ (Loubele et al., 2008). It is also to submit that voxel size can influence diagnostics and it is pertinent to state that a lowresolution option though preferred is likely to degrade the spatial resolution due to the motion during the scanning process.

However, optimum exposure is normally achieved by balancing the exposure time with the requirement of image quality. This is normally done by adjusting the $\mathrm{x}$ ray tube voltage and the tube current exposure time. For endodontics, ideally small volume/field of view CBCT scanners should be used (Loubele et al., 2009). Furthermore, ex vivo studies have suggested that if we change the degree of rotation of the X-ray source and detector from $360^{\circ}$ to $180^{\circ}$, there is significant reduction in the effective dose to half its original value (Durack et al., 2011; Gijbels et al., 2002). The protocols of such adjustments are still being formulated for further optimisation.

Alternately, shielding devices such as thyroid collar and lead can be used for reducing patient exposure (Health Protection Agency 2010; UK). The UK Health Protection Agency has carried out an audit of the dose- 
area-product (DAP) across 41 dental CBCT units and have recommended the adoption of $250 \mathrm{mGy} \mathrm{cm}^{2}$ for $\mathrm{CBCT}$ imaging in an average adult patient.

\section{Advantages of cone beam computed tomography}

1. One of the advantages of $\mathrm{CBCT}$ is that the effective radiation dose is lower than a panoramic $\mathrm{x}$-ray and considerably less than a medical CT scan (Ngan et al., 2003; Lofthag-Hansen et al., 2008).

2. Elimination of anatomical noise.

3. Accuracy of reproduction

4. Early detection of the size, position and extent of the periapical disease. CBCT could identify increased number of periapical lesions in maxillary and mandibular teeth as compared to conventional radiography (Lofthag-Hansen et al., 2007).

Endodontic treatment is successful when managed before radiographic signs of periapical disease are evident, thus improving the endodontic outcome (Friedman, 2002).

5. Accurate detection of alveolar bone topography.

6. Geometric accuracy as compared to conventional radiography (Murmulla et al., 2005).

7. $\mathrm{CBCT}$ can be used to detect periapical disease in patients with poorly localised symptoms with limited information revealed by clinical and periapical radiographs (Nakata et al., 2006).

8. Good appreciation of periapical lesions (Simon et al., 2003).

9. CBCT can be a useful tool in periapical surgery to detect the proximity of anatomical structures such as inferior dental canal, maxillary sinus and mental foreman.

10. Conventional radiography can determine the approximation of the inferior dental canal to the root apices in only $40 \%$ of the cases (Velvart et al., 2001).

\section{Limitations of CBCT}

1. Poor contrast resolution. The resolution of conventional and digital radiographs is $15-20$ line pairs per mm (Farman, 2005) as compared to cone beam computed tomography (2 line pairs $\mathrm{mm})$. Hence, presently, CBCT does not have the resolution as that of periapical radiography. This is due to several factors such as divergence of the $x$-ray beam (known as the 'heel effect'), low $\mathrm{mA}$, scatter-radiation and imperfections in the detector (Scarfe et al., 2009). This can be reduced by increasing the $\mathrm{mA}$ and exposure time (Patel et al., 2009a).
2. Beam hardening is the process of absorption of lower energy photons rather than higher energy photons when the beam encounters high-density objects. This results in distortion and appearance of artefacts' reducing the diagnostic productivity of the images. This is usually caused by metal posts, tooth enamel and restorations (Patel et al., 2009a).

3. Inferior spatial resolution.

4. Lengthy scan times (15-20 s) demanding minimal patient movement.

\section{Applications of CBCT in endodontics CBCT and tooth morphology Introduction}

An accurate portrayal of root canal anatomy is a perquisite for successful diagnosis and treatment. Every tooth is anatomically unique (Vertucci, 1974.). The internal anatomy of a tooth poses a challenge in successfully diagnosing, localising, negotiating, disinfecting and filling the root canal system (De Pablo et al., 2012).

Anatomical complexities can compromise treatment outcome (Wolcott et al., 2005). Owing to the twodimensional nature of conventional radiology, it cannot reveal the actual number of canals present in teeth (Patel et al., 2012a).

Studies have highlighted that CBCT is superior to conventional radiography in revealing the number of roots (Patel et al., 2012a; Matherne et al., 2008b). Matsumoto and Tachibana (Tachibana \& Matsumoto, 1990) were amongst the first people to use medical computed tomography to study the root canals, but poor resolution was a major obstacle. CBCT was used to scan teeth and thereafter, reconstruction was compared with the canal outline obtained using histological sections to find a strong correlation between the data acquired and CBCT. However this study had a small sample size

The clinician should be aware of the dental anomalies and the anatomic variations in every tooth to ensure endodontic success. One common method of evaluating root morphology is periapical radiography. This is a cost efficient and simple to use technique; however, superimposition and image distortion can be some potential disadvantages.

Descriptive studies (Matherne et al., 2008b; Neelakantan et al., 2010) have shown that CBCT can accurately highlight root morphology and overcome the flaws in conventional radiography.

\section{Number and shape of the root canals}

Some authors believe that conventional radiographs fail to identify the number of canals present in teeth (Patel et al., 2009a; Tu et al., 2009) subsequently compromising the outcome. Pre-operative knowledge of the canal 
anatomy can lead to a conservative cavity preparation and avoidance of mishaps such as ledge formation, canal transportation and perforation.

A study by Michetti et al. of the canal morphology of 72 teeth using charged couple device, photostimulable phosphor plate digital radiography system and $\mathrm{CBCT}$ was done. It was found that digital radiography with parallax technique failed to identify at least one in $40 \%$ of the canals in comparison with CBCT. However, this study did not verify the number of canals by using histological sections. Furthermore, this study was verified by only one OMFR and intra-examiner agreement was lacking. The teeth were not mounted in mandible/maxilla.

\section{Localisation of canals}

Pre-operative knowledge of the tooth anatomy can preempt endodontic complexities and improve treatment outcome. Anatomic challenges may hinder endodontic success. Maxillary first molar usually has three roots and four canals (Pécora et al., 1992). An in vivo study was done where maxillary first and second molars were sectioned and the number of canals was determined only to find that there was $80 \%$ correlation between CBCT and sectioning. The disadvantage was a small sample size ( $n$ $=20$ ). The sensitivity was $77 \%$ and specificity was $83 \%$ (Blattner et al., 2010).

CBCT had an intra-examiner agreement of $90 \%$. A study done by Filho (Filho et al., 2009) investigated the morphology of maxillary first molars using clinical, ex vivo and СВСТ. He reported the presence of a fourth canal in $67.14 \%$ of the teeth. He concluded that the reliability of CBCT imaging to detect the additional canals in the maxillary molar increased with magnification $\mathrm{Tu}$ et al. (Tu et al., 2009) revealed that the presence of distolingual canals was $21 \%$ with conventional radiographs and 33\% with CBCT. Furthermore, Albella (Abella et al., $2012 \mathrm{~b}$ ) found that CBCT was useful in the diagnosis of distolingual canals in molars. Unidentified/unfilled canals can be identified using axial slices of a CBCT scan.

\section{Calcified canals}

According to Ball (Ball et al., 2013) intra-operative CBCT can be useful for the assessment of the depth of the calcification to guide the clinician for locating and assessing the patent part of the canals. In addition, when a complete calcification is detected, CBCT can be used to study the apical pathosis to avoid perforation of a completely calcified canal. It can be used in cases with complex tooth anatomy within the realms of dose considerations.

\section{CBCT and canal curvature}

Estrela et al. (Estrela et al., 2008) assessed the curvature of the root canals with the aid of CBCT. CBCT is a reliable method to assess the radius of curvature which can reduce the aberrations and chances of instrument fracture.

\section{Complex root anatomy}

Dens invaginatus is a malformation caused due to the infolding of the enamel organ into the dental papilla during the stages of tooth development. According to Patel and Dawood (Patel \& Dawood, 2007b), CBCT can be useful in assessment of teeth with complex tooth anatomy. There is a shortage of studies which describe the endodontic treatment of dens invaginatus. Studies by some authors (Durack et al., 2011) justifies the use of cone beam computed tomography for teeth with complex aberrations (such as dens invaginatus) in cases where periapical radiography does not reveal the information required for the management and treatment of such teeth.

\section{Concluding remarks}

Conventional radiographs can assist the clinical to build a mental image of the tooth.

Accuracy is however dependent on factors such as the clinician's skill, knowledge, experience and the quality of the radiographs. $\mathrm{CBCT}$ is a useful tool in the interpretation of the anatomy of the tooth morphology where parallax technique and microscopes have failed to reveal the true picture. The root morphology can be well visualised and the canals can be mapped. A limited field of view with a high-resolution CBCT scanner can be used when periapical radiography is not able to provide the necessary information on the root canal anatomy. It is imperative to ensure that the radiation levels are justified and optimised. There is still scope for further evidence that will highlight the accuracy of $\mathrm{CBCT}$ for root canal morphology.

\section{CBCT and apical periodontitis Introduction}

Apical periodontitis is defined as a dynamic encounter between the microbes and host defence system at the interface between the infected radicular pulp and periodontal ligament. This results in inflammation, periapical destruction and resorption, eventually manifesting as various histopathological forms of periapical lesions (Nair, 2006).

The aim of endodontic treatment is to preserve the tooth in function and to promote periapical healing. Currently, the method of choice to view periapical changes is radiography (digital or conventional). Unfortunately, periapical radiography may not be able to reflect the changes in the cancellous bone (De Paula-Silva et al., 2009). In the initial stages of apical periodontitis, the periapical changes are minimal and working towards 
a diagnosis is a challenging task (Bender \& Seltzer, 1961; Patel et al., 2009c). This can be a cause for operator confusion and patient frustration in the diagnosis of the causative tooth (Abella et al., 2012a). CBCT is highly sensitive in recognition of apical periodontitis (Estrela et al., 2008). It can detect endodontic lesions before they become apparent on conventional radiographs (PaulaSilva et al., 2009). Early diagnosis of apical periodontitis can improve endodontic outcome (West et al., 2002).

One of the first studies to compare the prevalence of periapical lesions using $\mathrm{CBCT}$ and conventional radiographs was done by Lofthag-Hansen et al. (Lofthag-Hansen et al., 2007). They assessed periapical lesions on 46 maxillary and mandibular posterior teeth using parallax periapical radiography and CBCT. Periapical radiographs could diagnose lesions in thirty-two teeth. On the other hand, CBCT could detect lesions on an additional 10 (31\%). Assessment of the periapical status of individual roots revealed that CBCT could detect $62 \%$ more lesions than conventional radiographs. This could be attributed to minimisation of geometric distortion and anatomical noise in the maxillary and mandibular second molar region. Low et al. (Low et al., 2008a) and Bornstein et al. (Bornstein et al., 2011) reported similar findings.

Paula-Silva et al. (Paula-Silva et al., 2009) did a wellformulated animal study to confirm that CBCT was an accurate tool in the diagnosis of periapical periodontitis. In this in-vivo study, single and two-visit root canal treatment was done on 83 roots which confirmed radiographic signs of periapical periodontitis. A control group with similar findings was left untreated. On completion of 6 months, the animals were sacrificed and the roots with the periapical region were examined using histological measures. The specificity and positive predictive value (PPV) for CBCT and periapical radiographs was 1 . This means they were perfectly accurate to determine the absence of periapical disease. On the other hand, sensitivity for CBCT was higher than conventional radiography. Furthermore, the negative predictive value (NPV) for CBCT was 0.46 and for periapical radiography was 0.25 respectively. The accuracy in the detection of periapical periodontitis was 0.92 for $\mathrm{CBCT}$ and 0.78 for periapical radiography.

Ex vivo experiments (Stavropoulos \& Wenzel, 2007) were artificially created lesions in pig mandibles. CBCT and conventional radiographs were used to study the lesions. It was found that $\mathrm{CBCT}$ was twice more sensitive in the detection of artificially created lesions as compared to periapical radiography. Ex-vivo study on human jaws was done by Patel et al. (Patel et al., 2009b) to find that $\mathrm{CBCT}$ is more accurate in determination of periapical lesions than conventional radiographs. Additionally, CBCT has $100 \%$ specificity and sensitivity in the detection of periapical lesions that were created artificially in human mandibles. On the contrary, periapical radiography could detect only $24.8 \%$ of the lesions. This is a statistically significant difference!

Low et al. (Low et al., 2008a) and Estrela et al. (Estrela et al., 2008) found that CBCT displayed a higher sensitivity for diagnosis of apical periodontitis as compared to panoramic and periapical radiography.

Abella et al. (Abella et al., 2012a) assessed the ability of periapical radiographs and CBCT to diagnose apical periodontitis. He studied 307 paired roots with asymptomatic and symptomatic irreversible pulpitis. The results were that conventional radiography could identify lesions in 3\% of roots, whereas CBCT could detect apical periodontitis in $14 \%$ of the roots. Parallax radiography is recommended to allow the image to be reproduced; on the contrary, a single radiograph is handicapped by anatomical noise, geometric distortion and limited accuracy. With frequent superimposition of roots in the posterior quadrants, it can be difficult to identify periapical lesions (Davies et al., 2015). Ozen et al. 2009 (Ozen et al., 2009) compared the diagnostic potential of two CBCT units and intraoral (digital and conventional) radiographs for the diagnosis of periapical lesions that were chemically created. Both CBCT scanners had similar performances which were better than intraoral radiographs in the detection of periapical lesions.

\section{Concluding remarks}

The sensitivity of CBCT is higher than periapical radiography. The specificity of both systems is similar. Prompt identification of periapical pathology contributes to efficient endodontic management (Friedman, 2002). In cases of poorly localised symptoms when clinical and periapical radiography does not reveal any evidence of pathology, CBCT can be a savoir (Patel \& Dawood, 2007b). The detection of apical periodontitis by CBCT can influence endodontic diagnosis, instrumentation, disinfection and prognosis. CBCT should be reserved for diagnosing periapical pathology in symptomatic patients where clinical and radiographic imaging is unremarkable (Patel et al., 2009a).

\section{CBCT and endodontic outcome Introduction}

'Outcome is defined as the measurement of success of a treatment in a designated time frame'. In endodontics, outcome can be determined by evaluation of clinical symptoms and radiographic interpretation. Assessment of outcome is considered imperative as chronic apical periodontitis can exist even in the absence of clinical signs and symptoms (Friedman, 2002). Needless to state, any outcome can directly influence a treatment plan. To give an example, success of primary root canals is perceived to be in the range of $60-100 \%$ in traditional cases 
demonstrating healing outcomes, but when outcome assessment is done using CBCT a lower healing rate is noted (Patel et al., 2012a). Why is this so? CBCT can accentuate lesions which are otherwise not visible.

It is often said that time is an important factor in any healing assessment. Orstavik (Orstavik, 1996) stated that complete healing in some cases of chronic apical periodontitis required as much as 4 years. However, in such cases, initial signs of incomplete healing had started appearing in most of the teeth after as early as 1 year.

A periapical lesion is defined as a radiolucent area which is double the width of the periodontal space evident around the radiographic apex (Low et al., 2008a). Radiology is an irreplaceable adjunct to clinical examination and the current reference standard for an assessment of apical pathology is by radiographic examination (Weissman et al., 2015). Ironically, radiographs are limited by their two dimensional nature, besides anatomical noise and geometrical distortion.

To visualise bone pathology, parallax radiography is generally recommended (one $\mathrm{x}$-ray at a right angle and the other at a $10^{\circ}$ horizontal angulation) but there are some limitations to this technique. If the root of a multirooted tooth curves in the bucco-lingual plane, no radiograph will be able to cover the paralleling and bisecting angulation of the root. Additionally, Bender and Setzer have observed that if the cortical bone is intact, then lesions in the cancellous bone can go undetected (Bender \& Seltzer, 1961). Further, it requires as less as $7.1 \%$ bone loss in the cortical bone to produce a radiolucent area that can be detected by radiographs.

Studies have investigated the outcome of endodontic treatment using periapical radiography which have shown success rates of $28-83 \%$ (De Chevigny et al., 2008). Notwithstanding these findings, Lofthag-Hansen et al. (Lofthag-Hansen et al., 2008), Low et al. (Low et al., 2008a) and Estrela et al. (Estrela et al., 2008) have compared the outcome of root canal treatment by $\mathrm{CBCT}$ and conventional periapical radiography to come to the conclusion that CBCT can discover $20-35 \%$ more lesions.

Other major findings to name a few are CBCT can detect bone destruction before it becomes evident on conventional radiographs. CBCT can detect signs of disease (such as periapical radiolucency and widened periodontal ligament space) even though conventional radiograph displayed healing. Patel et al. (Patel et al., 2007) found that the periapical bone defects evaluated with $\mathrm{CBCT}$ were $10 \%$ smaller than coronal sections taken on conventional radiography.

Outcome of treatment is improved if clinical signs are treated before the development of the disease (Friedman) (Friedman, 2002). Outcome assessment is important before placing a coronal restoration (Faculty of General Dental Practitioners UK 2004).
A clinical study by Davies et al. (Davies et al., 2015) aimed to compare the outcome of 1 year post-operative root treatments using periapical radiography and conventional radiography verified that by using $\mathrm{CBCT}$, a lower outcome was detected as compared to conventional radiography.

According to Patel et al. (Patel et al., 2007) and Ørstavik (Orstavik, 1996), the diagnosis of apical periodontitis and outcome assessment are still reliant on conventional radiographs. CBCT is not routinely used for assessment of apical periodontitis, due to raised exposure parameters but it can be used in cases where pain and clinical signs of periapical inflammation do not correlate with periapical radiographs.

Additionally, CBCT can be been used for the volumetric measurement of periapical healing where measurement of the volume of a periapical lesion could give an insight towards periapical healing (Durack et al., 2011; Orstavik, 1996). Ahlowalia et al. (Ahlowalia et al., 2013) used ex-vivo models to artificially create bone cavities. Thereafter, cone beam computed tomography and micro-computed tomography were used to measure the volume of these bone cavities. Both imaging systems displayed high agreement when measurements were calibrated. The results of the study showed cone beam computed tomography was a much more accurate tool to both measure lesions in apical periodontitis as well as to monitor them, if required. Volumetric assessment of healing has also been performed by some other studies with small sample size.

Histopathological examination is another method to confirm the presence of apical lesions. Green et al. (Green et al., 1997b) studied cadaver teeth that had received endodontic treatment which were radiographically assessed. He concluded that radiographs can be used to assess the presence/ absence of apical periodontitis but they are not a reliable indicator of the true histological picture. Similar work was presented by Ricucci and his colleagues (Ricucci et al., 2009). Paula-Silva et al. (Paula-Silva et al., 2009) examined rootfilled dog's teeth using periapical radiography and CBCT. After the animals were sacrificed, a histological examination was performed. CBCT demonstrated increased sensitivity and accuracy in the diagnosis of apical periodontitis in contrast to periapical radiography.

A clinical study by Patel et al. (Patel et al., 2012a; Van der Borden et al., 2013) scanned a total of 151 teeth in 132 patients for periapical lesions using both $\mathrm{CBCT}$ and periapical radiography. A panel with two calibrated examiners interpreted the images under standardised conditions. Out of the 273 paired roots, $20 \%$ had periapical lesions; remaining $80 \%$ showed absence of apical periodontitis when periapical radiography was used. On the contrary, CBCT detected $48 \%$ additional lesions thereby confirming that $\mathrm{CBCT}$ can accurately detect apical periodontitis. 
"Healing rate" is defined as the reduction in the dimension of the radiolucency, whereas "healed rate" is the absence of radiolucency at review. Part two of this review compared the radiographic changes in the roots 1 year post treatment using $\mathrm{CBCT}$ as well as periapical radiographs. This time, 123 teeth were examined that were endodontically treated by a single operator and compared to the pre-operative radiographs. The periapical lesions were assessed by two examiners under standardised conditions. The teeth diagnosed using CBCT showed a lower healing and healed rate as compared to periapical radiographs. There was a significant increase (14 times) in the failure rate when teeth with no preoperative lesions were assessed using CBCT.

In continuation, Liang et al. (Liang et al., 2011) used $\mathrm{CBCT}$ and conventional radiography to compare the quality of root canal treatment. CBCT revealed a higher number of endodontic failures as compared to conventional radiography. In 2013, using the same imaging modalities, he studied the effect of ultrasonic activation on the outcome of treatment. He found that there was no difference noted on the outcome using ultrasonic activation.

Fernandez et al. (Fernández et al., 2013) assessed the outcome of endodontic treatment carried out on vital pulps using conventional radiographs, digital sensors and $\mathrm{CBCT}$. He used 17 prognostic factors that influenced endodontic outcome such as root canal curvature, unidentified canals, quality of coronal restoration and disinfection of gutta percha. There were varied results after 5 years with each imaging system. The major drawback of this study was an absence of a pre-operative $\mathrm{CBCT}$, hence no comparisons could be drawn and the results remained inconclusive.

\section{Concluding remarks}

There is a demonstrable need to have an accurate, quantitative and robust system to evaluate the outcome of endodontic treatment. Such a system provides innumerable benefits like accurate outcome assessment and measurement of healing. It can be concluded from the evidence mentioned in the paragraphs above that due to the limitations of conventional radiography, the size of the periapical radiolucency can be underestimated. On the other hand, CBCT has higher sensitivity as compared to conventional radiography in the detection of periapical pathology. Specificity, however, is similar for both the systems. CBCT may play a pivotal role in endodontic research it can used to evaluate the outcome in various treatment strategies such as preparation and instrumentation techniques. On the contrary, there is absence of concrete evidence justifying the use of CBCT in post endodontic treatment owing to increase radiation. Need of the hour is further evidence in the assessment of endodontic outcome.

\section{CBCT and pre-surgical assessment Introduction}

Cone beam computed tomography facilitates the clinician to view the relationship of the tooth to its surrounding anatomical structures in a three-dimensional view. Cone beam computed tomography with its visual clarity can assist the surgeon in the planning of surgical procedures. The competence of CBCT in the diagnosis of periapical lesions has already been discussed previously. It has been highlighted how the presence/absence of a periapical lesion can change the course of action(s) in any surgical procedures (Bornstein et al., 2011).

\section{The role of cone beam computed tomography in the surgical assessment of maxilla}

CBCT's guidance enables accurate measurement of the distance between the cortical plate and the palatal root apex. Even the proximity to the maxillary sinus can be evaluated (Lofthag-Hansen et al., 2007; Patel et al., 2007; Bornstein et al., 2011). Using CBCT the size, location and extent of the periapical lesion can be determined.

Rigolone et al. (Rigolone et al., 2003) planned an apicoectomy on 43 maxillary first molars via the vestibular approach for which he used low dose CBCT to measure the distance between the palatal root and the vestibular cortex. Furthermore, he was able to study the positioning of the maxillary sinus lateral recess. CBCT assisted in visualisation of the surgical plane with precision and minimal complications.

A study by Kenneth et al. (Low et al., 2008b) examined 156 roots (37 molars and 37 premolars) highlighted that CBCT can meticulously recognise apical pathology as compared to periapical radiology (discussed earlier). Clinicians faced difficulty with periapical radiographs, especially in second molar region and areas with close proximity to the maxillary sinus. CBCT could detect the expansion of the lesion into the sinus, missed canals and thickening of the sinus membrane.

\section{The role of $\mathrm{CBCT}$ in the surgical assessment of mandible} Bornstein (Bornstein et al., 2011) aimed to evaluate the dimension of the periapical lesions, the relationship of the mandibular roots to the inferior alveolar canal and buccal bone dimension with $\mathrm{CBCT}$ and periapical radiographs before attempting apical surgery. The study consisted of 38 molars with 75 roots. Radiographs were compared to the sagittal and coronal slices of a CBCT scan. The results stated that out of 58 lesions, $25.9 \%$ lesions diagnosed with $\mathrm{CBCT}$ were undetected on periapical radiography. The distance between the root apex and mandibular canal was measurable in $35.3 \%$ periapicals. The dimension of the buccal bone could be ascertained as well thereby stressing on the importance of CBCT assessment in the mandibular quadrant before surgery. 


\section{Concluding remarks}

CBCT has been recommended for endodontic surgery (Patel et al. and Low et al.) (Patel et al., 2007; Low et al., 2008b) CBCT can provide a three-dimensional view of bone topography, tooth anatomy and proximal anatomical structures. According to Horner et al. 2013, CBCT can provide an accurate idea about the quantity and shape of the bone. However, there is less certainty about the quality of the bone. Cone beam computed tomography can be used to visualise the root morphology and thereby influence the outcome of the treatment.

\section{CBCT and vertical root fractures Introduction}

Vertical root fractures extend longitudinally from the canal space to the periodontium (Low et al., 2008b). They provide a pathway between the oral cavity and the bacteria leading to destruction of the periodontal space and subsequent bone loss (Rud \& Omnell, 1970). The clinical presentation of vertical root fractures is an isolated periodontal probing depth on either side of the tooth, multiple sinuses and a characteristic 'halo' or 'J'-shaped radiolucency (Low et al., 2008b). However, these signs may not be associated with long standing or incipient fractures. Vertical root fractures are commonly associated with endodontically treated teeth (Komatsu et al., 2014). Some of common predisposing factors are overzealous root preparation, forces delivered during root canal obturation and intra-radicular post. The prognosis of vertical root fractures is dependent on the location of the fracture and the extent of radicular involvement. Timely and accurate diagnosis can prevent extraction of the concerned tooth. However, these fractures present as a diagnostic dilemma. Clinical features are inconclusive and conventional radiographs are limited in their diagnostic abilities due to compression of a three-dimensional anatomy into a two-dimensional image, geometric distortion and anatomical noise (Cohen et al., 2006).

Conventional radiography may not be diagnostically useful in the diagnosis of vertical root fractures unless the $x$-ray beam coincides with the fracture line. To overcome this hurdle, it is advised that two radiographs be taken with a shift in the horizontal beam. Nevertheless, even after using the parallax method, overlapping may be inevitable preventing the visualisation of the fracture line (Rud \& Omnell, 1970).

According to some authors, cone beam computed tomography can be promising in the diagnosis of vertical root fractures due to its three dimensional nature, minimal geometric distortion and reduction of anatomical noise (Wang et al., 2011a; Zou et al., 2011).

The diagnostic utility of CBCT in the diagnosis of vertical root fractures is determined by the following parameters:

- The exposure settings.

- Sensitivity of the detector.

- Voxel size/settings-some authors believe that a reduction in the voxel size can improve the diagnostic accuracy (Wenzel et al. 2009).

- Vertical root fracture width-complete or incomplete-diagnosis of complete root fractures is simpler than incomplete.

- The type of the scanner used (Accuitomo, i-CAT). However, there is not a significant difference in the scanner types.

- Root canal filling-intra-radicular posts and root canal fillings can greatly influence the diagnostic ability of CBCT due to beam hardening effects.

\section{Cone beam computed tomography and periapical radiography in the detection of vertical root fractures}

Hansen et al. conducted an in-vitro/ex-vivo study which aimed to compare the diagnostic accuracy of conventional radiography and CBCT. Furthermore, it also mentioned the impact of the root filling on the image quality. They studied 80 teeth (premolars and molars), which were divided into 4 groups (A, B, C, D). Groups A and $B$ had fractures artificially induced and groups $C, D$ did not. A and $\mathrm{C}$ were root filled. The sensitivity and specificity of CBCT was $79.4 \%$ and $92.5 \%$ as compared to periapical radiography (37.1\% and $95 \%$ ). The specificity of CBCT was reduced by the presence of a root filling. The results showed a higher accuracy for CBCT (Hassan et al., 2009).

A study by Ozer compared the accuracy of cone beam computed tomography using various voxel sizes for the detection of Vertical root fractures. Sixty teeth with/ without root fractures were examined with different voxel sizes $(0.125,0.2,0.3,0.4 \mathrm{~mm})$. A good diagnostic performance and a lower exposure were found with a voxel size of $0.2 \mathrm{~mm}$. However, this study made no mention about the width of the tooth (Özer, 2011).

An ex vivo study by Patel et al. in 2013 compared the diagnostic accuracy of cone beam computed tomography and periapical radiography using artificially prepared complete/incomplete root fractures in human teeth. Group 1 consisted of 20 extracted teeth (molars/premolars) that were radiographed and scanned with CBCT. Group 2 consisted of teeth scanned and radiographed after introducing incomplete fractures. Group 3 was comprised of teeth with complete fractures. Gutta 
percha was placed in the canals before exposing the concerned teeth. This study found that CBCT and periapical radiography were not able to detect artificially created fractures. The presence of a root filling decreases the accuracy of CBCT (Patel et al., 2013).

Patel and Brady did a study on an ex vivo model to compare the diagnostic accuracy of periapical radiography and $\mathrm{CBCT}$ for the detection of artificially induced complete/incomplete fractures. Furthermore, Patel and Brady studied the role of the width of the vertical root fracture on the accuracy of both imaging modalities. This study found that $\mathrm{CBCT}$ and periapical radiography were not reliable at detecting vertical root fractures. The width of the fracture influenced the diagnostic accuracy. Detection of vertical root fracture $\geq 50 \mathrm{~mm}$ was higher (Brady et al., 2014b).

Wang et al. (Wang et al., 2011b) examined 128 patients with suspected root fractures in 135 teeth. Amongst 135 teeth, 49 were root treated and 86 had no endodontic treatment done on them. These patients were exposed with $\mathrm{CBCT}$ and conventional radiographs and eventually underwent surgical exploration. Root fractures were detected in 95 out of 135 teeth. Sensitivity for periapical radiography was $26.3 \%$ and specificity was $100 \%$. On the other hand, sensitivity for CBCT was $89.5 \%$ and specificity was $97.5 \%$. CBCT was accurate at detection of root fractures; however, the sensitivity was reduced in the presence of a root filling; specificity remained unaffected. Specificity and sensitivity of conventional radiography was not influenced by a root filling. Studies with similar findings were presented by Edlund et al. (Edlund et al., 2011).

\section{Concluding remarks}

The available literature questions the ability of cone beam computed tomography in the diagnosis of vertical root fractures. The artefacts caused in the presence of root filling and intra-radicular post hinders diagnostic accuracy. Most case studies selected are influenced by operator bias due to absence of controls (Wang et al., 2011b; Edlund et al., 2011). The role of CBCT in the diagnosis of VRF needs further clarification and extended research.

\section{CBCT and resorption}

\section{Introduction}

Root resorption is defined as the loss of dentin and cementum as a result of osteoclastic activity (Patel \& Dawood, 2007a). The common method of classification is based on the location of the resorption that is external or internal. The process of resorption can continue for up to 2-3 weeks (Ozen et al., 2009) and may present itself as an inconspicuous finding. The process of resorption can be stimulated by pressure or infection triggering osteoclastic resorption of the injured root resulting in extensive damage.

\section{External cervical resorption}

External cervical resorption (ECR) is mostly initiated by damage to the cementum (usually caused by luxation and avulsion injuries) eventually leading to colonisation of the area by osteoblasts. Furthermore, this condition can be idiopathic in nature. Other causes are trauma, orthodontic treatment and intracoronal bleaching (Fuss et al., 2003). The diagnosis can be challenging due to the absence of the characteristic 'pink spot'. The radiographic signs are usually an ill-defined radiolucency in the cervical third of the root. If the walls of the root canals run through the radiolucent defect, the lesion is external in nature (Fuss et al., 2003).

Parallax radiography can be used to determine the type of resorption. However, the sensitivity of conventional radiographs is poor in the detection of external root resorption. Furthermore, till the time external root resorption becomes evident on the conventional radiographs, considerable hard tissue damage has already occurred. Also, it is difficult to differentiate between the type of resorption. On the contrary, CBCT can effectively diagnose the type of resorption and the area of extent of the lesion.

\section{Internal resorption}

Internal root resorption is the process of the destruction of the intra-radicular dentin and dentinal tubules. It occurs around the middle and apical region of the canal walls due to osteoclastic activity. A 'ballooning-out' appearance is characteristic of internal root resorption. The lesion is oval/round radiolucency with a smooth well defined outline.

\section{Cone beam computed tomography or conventional radiography?}

Resorption may present as a diagnostic dilemma leading to inappropriate treatment. Clinically differentiating between internal and external resorption can be difficult especially without the signs of pink spot, localised gingival inflammation and osseous defects (Gulabivala \& Searson, 1995). The first step towards the diagnosis of resorption is conventional radiography. Conventional radiography using the parallax technique can be used to confirm the location (palatal or labial) of the root resorption. Authors (Cohenca et al., 2007c) believe that parallax technique may be unsuccessful in the diagnosing of resorption (Cohenca et al. 2007). Additionally, it does not provide information about the dimension and extent of the lesion. The diagnostic information revealed is incomplete due to the compression of a three-dimensional anatomy into a two-dimensional shadowgraph. Moreover, anatomical noise 
results in an underestimation of the size of the resorption (Durack et al., 2011; Patel \& Dawood, 2007a).

An in vivo study by Patel et al. 2009 attempted to study the validity and reliability of CBCT. The sample comprised of 10 patients collected over 2 years. Five teeth were diagnosed with external resorption, five with internal and the rest were used as controls. This study verified that intraoral radiographs were reasonably accurate in the diagnosis of internal and external root resorption. However, CBCT scans diagnosed root resorption accurately. The software allows selection of a favourable orthogonal view and adjustment of the thickness between each slice, thus increasing diagnostic susceptibility. This study incorporated intraexaminer agreement with care to reduce recall bias. The only disadvantage was the limited sample size depicting the rarity of this condition. CBCT can be a useful in the assessment of root resorption shaping the treatment plan.

Kamboroglu et al. did an ex vivo study with 90 mandibular anterior teeth. In 50 teeth, artificial lesions were induced with a $0.5 \mathrm{~mm}$ round bur and 40 were left. These were then placed in the alveolar sockets of dry mandible and imaged with $\mathrm{CBCT}$ and periapical radiography. These images obtained were then evaluated by three different observers. It was found that there was a high intra/inter-observer agreement with CBCT images. This study concluded that $\mathrm{CBCT}$ was accurate at detection of artificially induced lesions. Nevertheless, there is no comparability with clinical situations. Additionally, clinically the bone changes might change the diagnostic ability of the imaging system (Kamburoğlu et al., 2011).

Durack et al. 2011 did an ex-vivo study to compare the accuracy of digital radiography and $\mathrm{CBCT}$ in the detection of external inflammatory root resorption. In addition, he studied the effect of the degree of rotation of CBCT scanners on the diagnosis of the lesions. External inflammatory resorptive lesions were created on 10 mandibular incisors. Small volume CBCT (180 and 360) and digital periapical images were recorded before and after the lesions were created. Regardless of the degree of rotation of the CBCT scanner, it was significantly better (high sensitivity and specificity) than digital radiography in detection of the lesions. $\mathrm{He}$ also suggested that resorptive lesions can rapidly progress causing massive tooth destruction hence early diagnosis can be a tooth saviour (Durack et al., 2011).

Furthermore, there are case reports by Cohenca et al. 2007, Patel et al. 2007 and Patel and Dawood 2007 (Durack et al., 2011; Patel \& Dawood, 2007a; Cohenca et al., 2007c) supporting the accuracy of CBCT-produced images.

\section{Concluding remarks}

CBCT can be a useful tool in the assessment of root resorption thus assisting shaping the treatment plan of a patient as it has higher sensitivity as compared to conventional radiographs. However, most resorptive lesions are unpredictable and occur as incidental findings on routine radiographic assessment. The use of CBCT for routine use is difficult to justify. Limited volume, highresolution CBCT can be used in cases of suspected or established resorption where $\mathrm{CBCT}$ can influence the management and prognosis of the tooth.

\section{CBCT and dento-alveolar trauma Introduction}

The diagnosis, treatment planning and determination of the prognosis of traumatised teeth is a challenging task. Most commonly used systems for trauma assessment are computed tomography, magnetic resonance imaging, periapical radiography and cone beam computed tomography. Trauma to the oral region comprises $5 \%$ of all dental injuries (Andreasen et al., 2012). The probability of trauma is high in children and adolescents. Incisors are the commonly affected teeth. Effective time management in diagnosis can influence the prognosis of the concerned tooth/teeth. Parallax and occlusal radiographs are recommended for the diagnosis of dental trauma by the International Association of dental traumatology (IADT). The IADT (2012) recommends several projections $\left(90^{\circ}\right.$ horizontal angulation, occlusal view and a lateral view mesial or distal to the concerned tooth). Even after multiple radiographs taken at several different angles, the fracture line may still not be diagnosed leading to inappropriate treatment and guarded prognosis of the teeth. Commonly misdiagnosed area is the maxillary anterior quadrant due to the oblique nature of the fracture in the sagittal plane.

Horizontal root fractures are classified according to their location and the extent of displacement of the coronal fragment. The prognosis of these fractures is dependent on several factors such as the age of the patient, root development, dislocation and mobility of the coronal fragment. They are common in the maxillary central region (68\%), followed by lateral incisors (27\%) and rarely mandibular incisors. Root fractures can be horizontal or diagonal in their direction. Detection of these fractures is possible only if the central beam passes through the fracture line. This usually happens with the fractures of the cervical third (Cvek et al., 2008).

Cone beam computed tomography can be an asset in the diagnosis and management of dento-alveolar trauma. It has the added advantage of minimisation of anatomical noise and geometric distortion. A single scan can assess the nature and severity of the injuries. Furthermore, 
the direction of the displacement can be clearly visualised.

Since CBCT is an extra oral technique, it is considered far more comfortable for a patient who has recently sustained dental trauma as compared to several periapical radiographs taken using a paralleling device. According to Cohenca et al. (Cohenca et al., 2007b), cone beam computed tomography could effectively detect the nature of the trauma and associated cortical bone defects with $\mathrm{CBCT}$ for the management of 3 patients which were not evident using conventional radiography. Furthermore, CBCT is accurate as compared to multiple periapicals in determination of horizontal root fractures (Kamburoğlu et al., 2009). Rarely single tooth trauma is seen. With the aid of CBCT, multiple teeth are covered in a single scan without the disadvantages of geometric distortion.

\section{Concluding remarks}

CBCT can reveal useful information influencing the outcome of dental trauma. According to the European Society of Endodontology, CBCT can be used in patients with complex dental trauma. CBCT is a potentially beneficial imaging system in the management of dental trauma.

\section{Discussion}

Any effective endodontic treatment is dependent on the accuracy of imaging systems and usually requires radiographic assistance in three stages: stage 1-before commencing the treatment to assess tooth morphology and periapical lesion; stage 2-working length/master cone radiograph; and stage 3-that is post-obturation radiograph. For such straightforward endodontic cases, exposure of the patient to CBCT it is not justifiable (Cotton et al., 2007).

It is therefore very evident that $\mathrm{CBCT}$ should not be routinely used for assessment of root canal morphology and should be reserved for class III and IV dens invaginatus and complex root canal systems (European Society of Endodontology, 2006).

However, when normal periapical radiography is not in a position to demonstrate accurately the root canal morphology and the clinician is not in a position to formulate his/her treatment plan which would consequentially influence the outcome of the treatment, only then a limited volume, high-resolution $\mathrm{CBCT}$ should be attempted [http://www.sedentexct.eu/files/radiation_protection_172.pdf].

Reviews by Patel et al. 2007 (Patel et al., 2007) and Cotton et al. 2007 (Cotton et al., 2007) stress on the favourable outcome by the use of CBCT. The only concern with $\mathrm{CBCT}$ produced images is the low resolution of $\mathrm{CBCT}$ as compared to periapical radiographs.
Diagnosing periapical pathology is a common task for dentists. Case reports and non-systematic reviews by Patel et al. 2007 (Patel et al., 2007) and Cotton et al. 2007 (Cotton et al., 2007) have highlighted the importance of CBCT in the diagnosis of periapical pathology. Ốzen et al. 2009 (Ozen et al., 2009) found raised intra examiner agreement and accuracy in detecting artificial lesions by using CBCT as compared to periapical radiography. Laboratory studies by Stavropolous \& Wenzel 2007 (Stavropoulos \& Wenzel, 2007), Patel et al. 2009a (Patel et al., 2009c) and De PaulaSilva et al. 2009 (De Paula-Silva et al., 2009) on human and animals did verify that $\mathrm{CBCT}$ can accurately diagnose periapical lesions. CBCT can be considered if the periapical radiography is inconclusive and this is contradictory to the clinical signs and symptoms (Cotton et al., 2007).

Cone beam computed tomography is an adjunct in planning of surgical procedures since anatomical structures are clearly visualised and measured as well as dimensions and extent of lesions can be easily determined. Studies by Rigolone et al. (Rigolone et al., 2003) and Bornstein (Bornstein et al., 2011) support this statement.

Hence, limited volume high-resolution cone beam computed tomography can be used in selected cases for presurgical assessment but deciding factors are generally proximity to the anatomical structures (http://www. sedentexct.eu/files/radiation_protection_172.pdf).

Cone beam computed radiography is diagnostically accurate in the determination of dental trauma. In selected cases where periapical radiology has provided inadequate information to assist in treatment planning (http://www. sedentexct.eu/files/radiation_protection_172.pdf). Studies by Patel et al. 2007 (Patel et al., 2007), Cohenca et al. 2007 (Cohenca et al., 2007b) and Kamboroglu et al. (Kamburoğlu et al., 2009) verify this statement.

Cone beam computed tomography can guide in diagnosing the type and extent of resorption. Limited volume high-resolution cone beam computed tomography can be used for the diagnosis of internal/external resorption in deciding the course of action and planning the management of the concerned tooth (Cotton et al., 2007).

A CBCT scan should be considered only after a clinical examination has been carried out and conventional radiographs have been taken (ICRP 2007). The 'As Low as reasonably achievable' (ALARP) guidance should always be kept in mind. The guidelines mentioned below, which have been extracted from the European Society of Endodontology and SEDENTEX, should normally be considered by clinicians who are using CBCT.

\section{Prerequisites for $\mathrm{CBCT}$ diagnostics}

- Justification of every radiation exposure after undertaking patient history and clinical examination including periapical radiography. They should add 
additional information to assist in the patient's management.

2. Risk/benefit assessment should be done for every patient.

3. CBCT should not be used for routine screening of imaging.

4. Radiation dose to the patient should be as low as reasonably practicable.

5. Accurate positioning and patient preparation should be done

6. Appropriately trained individuals should engage in conducting a scan.

7. All exposures should be reported by a trained individual.

\section{Concluding remarks}

For many years, endodontic treatment has been reliant on conventional radiographs. Evidence gathered from various studies has thrown light on the inadequacies of this imaging system. Cone beam computed tomography has effortlessly overcome the limitations of periapical radiography. Studies have accentuated the reliability of $\mathrm{CBCT}$ in the field of endodontics; some common examples covered in this review are in the diagnosis of periapical lesions, assessment of endodontic outcome, complex tooth morphology, dental trauma, vertical root fractures, pre-surgical assessment and resorption.

Any radiographic procedure runs the inherent risk of radiation exposure. It is for clinician to carefully weigh the pros and cons of the imaging modality that needs to be undertaken which depends on case selection. This review highlights the potential applications of $\mathrm{CBCT}$ in the assessment and management of endodontic problems notwithstanding the higher radiation dosage as compared to periapical radiography. CBCT appears to have an admirable validity and reliability in endodontic diagnosis. Current evidence suggests that CBCT has superior sensitivity in comparison to conventional radiography; $\mathrm{CBCT}$ can judicially overcome the flaws of conventional radiography, however the specificity is the same in both imaging systems (Patel et al. 2012 b).

Recently, there has been an increase in the use of CBCT in accordance with the evidence base. Guidance may be required whilst using $\mathrm{CBCT}$ scanners with respect to radiation safety and legislation. It is advised that CBCT should not be used as a direct replacement if a lower dose radiographic technique would provide sufficient diagnostic information. It is beneficial if the smallest field of view is used whilst capturing all the diagnostic information.

Two important principles of radiation protection are optimisation and keeping radiation levels to as low as reasonably practicable (ALARP). Besides, CBCT scanners should be assessed routinely using quality assurance programme. Even the American Association of Endodontists and the American Academy of Oral and Maxillofacial radiology issued a statement in 2011 that stated that CBCT should be prescribed only after weighing the risks and benefits of every exposure. Soon after in order to assist clinicians in justifying the use of $\mathrm{CBCT}$, the European Commission released 'evidence based' guidelines.

Needless to state, dentists who prescribe cone beam computed tomography should be adequately trained in factors that influence radiation dose, quality of the image, selection of the appropriate imaging modality, exposure factors and evaluation of the image obtained. Post-graduate programmes should incorporate the use of $\mathrm{CBCT}$ in their curriculum and clinicians should update their knowledge on the justifiable use of CBCT.

Ironically, CBCT cannot be routinely used for endodontic treatment because of increased radiation exposure. Prescribing $\mathrm{CBCT}$ can be an added responsibility for the clinician due to an increase in radiation hazard.

Please note that CBCT must not be used as a substitute to conventional radiography. However, it can be used in some circumstances where clinical and periapical radiographic assessment is inconclusive. $\mathrm{CBCT}$, therefore, offers an advanced direction to improve standards of care. It is safe to state that in the hands of a responsible practitioner CBCT can do wonders to the world of endodontics, expanding diagnostic and treatment possibilities. It is, perhaps, time to welcome $\mathrm{CBCT}$ as a part of the endodontic armamentarium, albeit judicially!

\section{Abbreviations \\ CBCT: Cone beam computed tomography; ALARP: As low as reasonably practicable; VRF: Vertical root fracture}

\section{Acknowledgements \\ Not applicable. \\ Author's contributions \\ ABK compiled the data from various studies/articles and wrote the review. The author(s) \\ read and approved the final manuscript.}

Funding

Not applicable.

Availability of data and materials

The data that supports this document can be found in the section of Bibliography. 


\section{Ethics approval and consent to participate}

This manuscript does not report on or involve the use of any animal or human data or tissue; hence, this section is not applicable for this review article.

\section{Consent for publication}

This article does not contain any individual data; hence, this section is not applicable.

\section{Competing interests}

The author declares that she has no competing interests.

\section{Author details}

${ }^{1}$ Royal College of Surgeons of England, London, UK. ${ }^{2}$ Royal College of Surgeons of Edinburgh, Edinburgh, UK. ${ }^{3}$ Endodontics King's College London, London, UK. ${ }^{4}$ Department of Dental Sciences, Medanta-The Medicity Hospital, Gurgaon, India.

Received: 1 July 2020 Accepted: 11 August 2020

Published online: 21 September 2020

\section{References}

Abella F, Patel S, Duran-Sindreu F. Mercade 0 M, Roig M Mandibular first molars with disto-lingual roots: review and clinical management. Int Endod J. 2012b; 45:963-78.

Abella F, Patel S, Duran-Sindreu F, Mercad M, Bueno R, Roig M. Evaluating the periapical status of teeth with irreversible pulpitis by using cone-beam computed tomography scanning and periapical radiographs. J Endod. 2012a 38:1588-91.

Ahlowalia MS, Patel S, Anwar HM, Cama G, Austin RS, Wilson R, Mannocci F Accuracy of $C B C T$ for volumetric measurement of simulated periapical lesions. Int Endod J. 2013:46(6):538-46.

Andreasen JO, Ahrensburg SS, Tsilingaridis G. Root fractures: the influence of type of healing and location of fracture on tooth survival rates - an analysis of 492 cases. Dent Traumatol. 2012;28:404-9.

Ball RL, Barbizam JV, Cohenca N. Intraoperative endodontic applications of conebeam computed tomography. J Endod. 2013 Apr;39(4):548-57.

Barton DJ, Clark SJ, Eleazer PD, Scheetz JP. Farman AG Tuned-aperture computed tomography versus parallax analog and digital radiographic images in detecting second mesiobuccal canals in maxillary first molars. Oral Surg Oral Med Oral Pathol Oral Radiol Endod. 2003;96:223-8.

Bender IB, Seltzer S. Roentgenographic and direct observation of experimental lesions in bone: I. J Am Dent Assoc. 1961:62:152-60.

Blattner TC, George N, Lee CC, Kumar V, Yelton CD. Efficacy of cone-beam computed tomography as a modality to accurately identify the presence of second mesiobuccal canals in maxillary first and second molars: a pilot study. J Endod. 2010:36(5):867-70.

Bornstein MM, Lauber R, Sendi P, von Arx T. Comparison of periapical radiography and limited cone-beam computed tomography in mandibular molars for analysis of anatomical landmarks before apical surgery. J Endod. 2011;37:151-7.

Brady E, Mannocci F, Brown J, Wilson R, Patel S. A comparison of Cone Beam Computed Tomography and periapical radiography for the detection of vertical root fractures in nonendodontically treated teeth. Int Endod J. 2014a; 47:735-46.

Brady E, Mannocci F, Brown J, Wilson R, Patel S. A comparison of Cone Beam Computed Tomography and periapical radiography for the detection of vertical root fractures in nonendodontically treated teeth. Int Endod J. 2014b; 47:735-46.

Cohen S, Berman LH, Blanco L, Bakland L, Kim JS. A demographic analysis of vertical root fractures. J Endod. 2006;32:1160-3.

Cohenca N, Simon JH, Mathur A, Malfaz JM. Clinical indications for digital imaging in dento-alveolar trauma. Part 2: root resorption. Dent Traumatol. 2007c;23(2):105-13.

Cohenca N, Simon JH, Roges R, Morag Y, Malfaz JM. Clinical indications for digital imaging in dento-alveolar trauma. Part 1: traumatic injuries. Dent Traumatol. 2007a;23:95-104.

Cohenca N, Simon JH, Roges R, Morag Y, Malfaz JM. Clinical indications for digital imaging in dento-alveolar trauma. Part 1: traumatic injuries. Dent Traumatol. 2007b;23:95-104.
Cotton TP, Geisler TM, Holden DT, Schwartz SA, Schindler WG. Endodontic applications of cone-beam volumetric tomography. J Endod. 2007 Sep;33(9): 1121-32.

Cvek M, Tsilingaridis G, Andreasen JO. Survival of 534 incisors after intra-alveolar root fracture in patients aged 7-17 years. Dent Traumatol. 2008;24:379-87.

Davies A, Mannocci F, Mitchell P, Andiappan M, Patel S. The detection of periapical pathoses in root filled teeth using single and parallax periapical radiographs versus Cone Beam Computed Tomography - a clinical study. Int Endod J. 2015:48(6):582-92.

De Chevigny C, Dao TD, Basrani BR, et al. Treatment outcome in endodontics the toronto study-phases 3and 4: orthograde retreatment. J Endod. 2008;34:131-

De Pablo OV, Estevez R, Heilborn C, Cohenca N. Root anatomy and canal configuration of the permanent mandibular first molar: clinical implications and recommendations. Quintessence Int. 2012 Jan;43(1):15-27.

De Paula-Silva FW, Santamaria M Jr, Leonardo MR, Consolaro A, da Silva LA Cone-beam computerized tomographic, radiographic, and histologic evaluation of periapical repair in dogs' post-endodontic treatment. Oral Surg Oral Med Oral Pathol Oral Radiol Endod. 2009 Nov;108(5):796-805.

Durack C, Patel S, Davies J, Wilson R, Minnocci F. Diagnostic accuracy of small volume Cone Beam Computed Tomography and intraoral periapical radiography for the detection of stimulated external inflammatory root resorption. Int Endod J. 2011:44:136-47.

Durack C, Patel S. Cone Beam Computed Tomography in Endodontics. Braz Dent J. 2012;23(3):179-91.

Edlund M, Nair MK, Nair UP. Detection of vertical root fractures by using conebeam computed tomography :a clinical study. J Endod. 2011;37:768-72.

Estrela C, Bueno MR, Leles CR, Azevedo B, Azevedo JR. Accuracy of Cone Beam Computed Tomography and panoramic radiography for the detection of apical periodontitis. J Endod. 2008:34:273-9.

European Society of Endodontology. Quality guidelines for endodontic treatment: consensus report of the European Society of Endodontology. Int Endod J. 2006;39(12):921-30.

Farman AG. Farman TT A comparison of 18 different X-ray detectors currently used in dentistry. Oral Surg Oral Med Oral Pathol Oral Radiol Endod. 2005;99: $485-9$.

Fernández R, Cadavid D, Zapata SM, Alvarez LG, Restrepo FA. Impact of three radiographic methods in the outcome of nonsurgical endodontic treatment: a five-year follow-up. J Endod. 2013 Sep;39(9):1097-103.

Filho FB, Zaitter S, Haragushiku GA, Campos EA, Abuabara A, Correr GM. Analysis of the internal anatomy of maxillary first molars by using different methods. J Endod. 2009:35:337-42.

Friedman S. Prognosis of initial endodontic therapy. Endod Top. 2002;2:59-98.

Fuss Z, Tsesis I, Lin S. Root resorption-diagnosis, classification and treatment choices based on stimulation factors. Dent Traumatol. 2003:19:175-82.

Gijbels F, Jacobs R, Sanderink G, De Smet E, Nowak B, Van Dam J, et al. A comparison of the effective dose from scanography with periapical radiography. Dentomax Radiol. 2002;31:159-63.

Glickman GW. Pettiette MT Chapter 5. Preparation for treatment. In: Cohen S, Hargreaves KM, editors. Pathways of the Pulp. 9th ed. St. Louis: Mosby Elsevier; 2006. p. 97-135.

Goldman M, Pearson AH, Darzenta M. Endodontic success - who's reading the radiograph? Oral Surgery, Oral Medicine. Oral Pathol. 1972;33:432-7.

Green TL, Walton RE, Taylor JK, Merrell P. Radiographic and histologic periapical findings of root canal treated teeth in cadaver. Oral Surg Oral Med Oral Pathol Oral Radiol Endod. 1997a;83:707-11.

Green TL, Walton RE, Taylor JK, Merrell P. Radiographic and histologic periapical findings of root canal treated teeth in cadaver. Oral Surg Oral Med Oral Pathol Oral Radiol Endod. 1997b;83:707-11.

Grondahl H-G, Huumonen S. Radiographic manifestations of periapical inflammatory lesions. Endod Top. 2004;8:55-67.

Gröndahl H-G, Huumonen S. Radiographic manifestations of periapical inflammatory lesions. Endod Top. 2004;8:55-67.

Gulabivala K, Searson LJ. Clinical diagnosis of internal resorption: an exception to the rule. Int Endod J. 1995 Sep;28(5):255-60.

Hassan B, Metska ME, Ozok AR, van der Stelt P, Wesselink PR. Detection of vertical root fractures in endodontically treated teeth by a Cone Beam Computed Tomography scan. J Endod. 2009:35:719-22.

Heithersay GS. Clinical, radiographic, and histopathologic features of invasive cervical resorption. Quintessence Int. 1999:30:27-37.

Heithersay GS. Invasive cervical resorption. Endod Top. 2004;7:73-92. 
Holroyd JR, Gulson AD. Guidance on the Safe Use of Dental Cone Beam CT HPACRCE-010 Prepared by the HPA Working Party on Dental Cone Beam CT Equipment. Leeds, UK: Chilton Health Protection Agency; 2010.

Horner K. Cone-beam computed tomography: time for an evidence-based approach. Prim Dent J. 2013 Jan;2(1):22-31.

ICRP. Publication 103: The 2007 recommendations of the International Commission on Radiological Protection. Ann ICRP. 2007;37.

IRMER. The lonising Radiation (Medical Exposure) Regulations SI 2000/1059. London: HMSO; 2000.

Kamburoğlu K, Cebeci AR, Gröndahl HG. Effectiveness of limited cone-beam computed tomography in the detection of horizontal root fracture. Dent Traumatol. 2009;25:256-61.

Kamburoğlu K, Kurşun S, Yüksel S, Oztaş B. Observer ability to detect ex vivo simulated internal or external cervical root resorption. J Endod. 2011 Feb; 37(2):168-75.

Kobayashi K, Shimoda S, Nakagawa Y, Yamamoto A. Accuracy in measurment of distance using cone-beam computerized tomography. Int J Oral Maxillofac Surg. 2004;19:228-31.

Komatsu K, Abe Y, Yoshioka T, Ishimura H, Ebihara A, Suda H. Differential diagnosis of vertical root fractures using reconstructed three-dimensional models of bone defects. Dentomaxillofac Radiol. 2014;43(8):20140256.

Kundel HL, Revesz G. Lesion conspicuity, structured noise, and film reader error. Am J Roentgenol. 1976;126:1233-8.

Liang Y-H, Li G, Wesselink PR, Wu M-K. Endodontic outcome predictors identified with periapical radiographs and cone-beam computed tomography scans. Endod. 2011;37:326-31

Lofthag-Hansen S, Huumonen S, Grondahl K, Grondahl HG. Limited cone-beam $C T$ and intraoral radiography for the diagnosis of periapical pathology. Oral Surg Oral Med Oral Pathol Oral Radiol Endod. 2007;103:114-9.

Lofthag-Hansen S, Thilander-Klang A, Ekestubbe A, Helmrot E, Grondahl K. Calculating effective dose on a Cone Beam Computed Tomography device: 3D Accuitimo and 3D Accuitomo FPD. Dentomaxillofacial Radiol. 2008:37:729.

Loubele M, Bogaerts R, Van Dijck E, et al. Comparison between effective radiation dose of CONE BEAM COMPUTED TOMOGRAPHY and MSCT scanners for dentomaxillofacial applications. Eur J Radiol. 2009:71:461-8.

Loubele M, Jacobs R, Maes F, Denis K, White S, Coudyzer W, Lambrichts I, van Steenberghe D, Suetens P. Image quality vs radiation dose of four Cone Beam Computed Tomography scanners. Dentomaxillofac Radiol. 2008;37(6): 309-18.

Low KM, Dula K, Bürgin W, von Arx T. Comparison of periapical radiography and limited cone-beam tomography in posterior maxillary teeth referred for apical surgery. J Endod. 2008b;34(5).

Low MTL, Dula KD, Bürgin W, von Arx T. Comparison of periapical radiography and limited cone-beam tomography in posterior maxillary teeth referred for apical surgery. J Endod. 2008a;34:557-62.

Matherne RP, Angelopoulos C, Kulilid JC, Tira D. Use of cone-beam computed tomography to identify root canal systems in vitro. J Endod. 2008a:34:87-9.

Matherne RP, Angelopoulos C, Kulilid JC, Tira D. Use of Cone Beam Computed Tomography to Identify Root Canal Systems In Vitro. J Endod. 2008b;34:87-9.

Matherne RP, Angelopoulos C, Kulilid JC, Tira D. Use of cone-beam computed tomography to identify root canal systems in vitro. J Endod. 2008c;34:87-9

Michetti J, Maret D, Mallet JP, Diemer F. Validation of Cone Beam Computed Tomography as a tool to explore root canal anatomy. J Endod. 2010 Jul; 36(7):1187-90.

Mozzo P, Procacci C, Tacconi A, Martini PT, Andreis IA. A new volumetric CT machine for dental imaging based on the cone-beam technique: preliminary results. Eur Radiol. 1998;8(9):1558-64.

Murmulla R, Wortche R, Muhling J, Hassfeld S. Geometric accuracy of the NewTom 9000 Cone Beam CT. Dentomaxillofacial Radiol. 2005;34:28-31.

Nair PN. On the causes of persistent apical periodontitis: a review. Int Endod J. 2006 Apr;39(4):249-81.

Nakata K, Naitoh M, Izumi M, Inamoto K, Ariji E, Nakamura H. Effectiveness of dental computed tomography in diagnostic imaging of periradicular lesion of each root of a multirooted tooth: a case report. J Endod. 2006;32:583-7.

Nance R, Tyndall D, Levin LG, Trope M. Identification of root canals in molars by tuned-aperture computed tomography. Int Endod J. 2000;33:392-6.

Neelakantan P, Subbarao C, Ahuja R, Subbarao CV, Gutmann JL. Cone-beam computed tomography study of root and canal morphology of maxillary first and second molars in an Indian population. J Endod. 2010 Oct;36(10):1622-7.
Ngan DCS, Kharbanda OP, Geenty JP, Darendeliler MA. Comparison of radiation levels from computed tomography and conventional dental radiographs. Aust Dent J. 2003;19:67-75.

Orstavik D. Time-course and risk analyses of the development and healing of chronic apical periodontitis in man. Int Endod J. 1996;29(3):150-5.

Ozen T, Kamburoğlu K, Cebeci AR, Yüksel SP, Paksoy CS. Interpretation of chemically created periapical lesions using 2 different dental cone-beam computerized tomography units, an intraoral digital sensor, and conventional film. Oral Surg Oral Med Oral Pathol Oral Radiol Endod. 2009 Mar;107(3):42632.

Özer SY. Detection of vertical root fractures by using Cone Beam Computed Tomography with variable voxel sizes in an in vitro model. J Endod. 2011 Jan:37(1):75-9.

Patel S, Brady E, Wilson R, Brown J, Mannocci F. The detection of vertical root fractures in root filled teeth with periapical radiographs and CBCT scans. Int Endod J. 2013:46:1140-52.

Patel S, Dawood A. The use of Cone Beam Computed Tomography in the management of external cervical resorption lesions. Int Endod J. 2007a;40: 730-7.

Patel S, Dawood A. The use of Cone Beam Computed Tomography in the management of external cervical resorption lesions. Int Endod J. 2007b;40: 730-7.

Patel S, Dawood A, Mannocci F, Wilson R, Pitt Ford T. Detection of periapical bone defects in human jaws using Cone Beam Computed Tomography and intraoral radiography. Int Endod J. 2009c;42:507-15.

Patel S, Dawood A, Whaites E, Pitt Ford T. The potential applications of Cone Beam Computed Tomography in the management of endodontic problems. Int Endod J. 2007:40:818-30.

Patel S, Dawood A, Whaites E, Pitt Ford T. New dimensions in endodontic radiography-part 1 . Conventional and alternative radiographic systems. Int Endod J. 2009a;42:447-62.

Patel S, Horner K. Editorial: The use of Cone Beam Computed Tomography in Endodontics. Int Endod J. 2009;42:755-6.

Patel S, Mannocci F, Wilson R, Dawood A, Pitt Ford T. Detection of periapical bone defects in human jaws using Cone Beam Computed Tomography and intraoral radiography. Int Endod J. 2009b;42(6):507-15 Accepted for publication.

Patel S, Wilson R, Dawood A, Foschi F, Mannocci F. The detection of periapical pathosis using digital periapical radiography and Cone Beam Computed Tomography -part 2: a 1-year post-treatment follow-up. Int Endod J. 2012; 45(8):711-23.

Patel S, Wilson R, Dawood A, Mannocci F. The detection of periapical pathosis using periapical radiography and Cone Beam Computed Tomography - Part 1: pre-operative status. Int Endod J. 2012a;45:702-10.

Paula-Silva FWG, Hassam B, da Silva LAD, Leonardo MR, Wu M-K. Outcome of root canal treatment in dogs determined by periapical radiography and cone-beam computed tomography scans. J Endod. 2009:35:723-6.

Pécora JD, Woelfel JB, Sousa Neto MD, Issa EP. Morphologic study of the maxillary molars. Part II: Internal anatomy. Braz Dent J. 1992;3(1):53-7.

Pitts DL, Natkin E. Diagnosis and treatment of vertical root fractures. J Endod. 1983:9:338-46.

Ponder SN, Benavides E, Kapila S, Hatch NE. Quantification of external root resorption by low- vs high-resolution cone-beam computed tomography and periapical radiography: a volumetric and linear analysis. Am J Orthod Dentofacial Orthop. 2012;143:77-91.

Revesz G, Kundel HL, Graber MA. The Influence of Structured Noise on theDetection of Radiologic Abnormalities. Investig Radiol. 1974;6:479-86.

Ricucci D, Lin LM, Spångberg LS. Wound healing of apical tissues after root canal therapy: a long-term clinical, radiographic, and histopathologic observation study. Oral Surg Oral Med Oral Pathol Oral Radiol Endod. 2009;108:609-21.

Rigolone M, Pasqualini D, Bianchi L, Berutti E, Bianchi SD. Vestibular surgical access to the palatine root of the superior first molar: "low-dose cone-beam" CT analysis of the pathway and its anatomic variations. J Endod. $2003 \mathrm{Nov}$; 29(11):773-5.

Rud J, Omnell KA. Root fractures due to corrosion. Diagnostic aspects. Scand J Dent Res. 1970;78:397-403.

Rudolph DJ, White SC. Film-holding instruments for intraoral subtraction radiography. Oral Surg Oral Med Oral Pathol. 1988;65:767-72.

Scarfe WC, Levein M, Gane D, Farman AG. Use of Cone Beam Computed Tomography in Endodontics. Int J Dent. 2009;2009:1-20. 
Simon JH, Enciso R, Malfaz J-M, Roges R, Bailey-Perry M, Patel A. Differential diagnosis of large periapical lesions using cone-beam computed tomography measurements and biopsy. J Endod. 2003;32:833-7.

Stavropoulos A, Wenzel A. Accuracy of cone beam dental $C T$, intraoral digital and conventional film radiography for the detection of periapical lesions: an ex vivo study in pig jaws. Clin Oral Investig. 2007;11:101-6.

Tachibana H, Matsumoto K. Applicability of X-ray computerized tomography in endodontics. Endod Dent Traumatol. 1990 Feb;6(1):16-20.

Tu M-G, Huang H-L, Hsue S-S, Hsu J-T, Jou M-J, Tsai C-C. Detection of permanent three-rooted mandibular first molars by cone-beam computed tomography imaging in Taiwanese individuals. J Endod. 2009;35:503-7.

Van der Borden WG, Wang X, Wu MK, Shemesh H. Area and 3-dimensional volumetric changes of periapical lesions after root canal treatments. J Endod. 2013 Oct;39(10):1245-9.

Velvart $\mathrm{P}$, Hecker $\mathrm{H}$. Tillinger $\mathrm{G}$ Detection of the apical lesion and the mandibular canal in conventional radiography and computed tomography. Oral Surg Oral Med Oral Pathol Endodontology. 2001;92:682-8.

Velvart P, Hecker $\mathrm{H}$, Tillinger G. Detection of the apical lesion and the mandibular canal in conventional radiography and computed tomography. Oral Surg Oral Med Oral Pathol Oral Radiol Endod. 2001;92:682-8.

Vertucci FJ. Root canal anatomy of the mandibular anterior teeth. J Am Dent Assoc. 1974 Aug;89(2):369-71.

Wang P, Yan XB, Lui DG, Zhang WL, Zhang Y, Ma XC. Detection of dental root fractures by using cone-beam computed tomography. Dento Maxillo Facial Radiology. 2011a;40:290-8.

Wang P, Yan XB, Lui DG, Zhang WL, Zhang Y, Ma XC. Detection of dental roo fractures by using conebeam computed tomography. Dentomaxillofacial Radiol. 2011b;40:290-8.

Webber RL. Messura JK An in vivo comparison of digital information obtained from tuned-aperture computed tomography and conventional dental radiographic imaging modalities. Oral Surg Oral Med Oral Pathol Oral Radiol Endod. 1999;88:239-47.

Weissman J, Johnson JD, Anderson M, Hollender L, Huson T, Paranjpe A, Patel S, Cohenca N. Association between the Presence of Apical Periodontitis and Clinical Symptoms in Endodontic Patients Using Cone-beam Computed Tomography and Periapical Radiographs. J Endod. 2015. https://doi.org/10. 1016/j.joen.2015.06.004 [Epub ahead of print]

West JD, Buchanan LS, Arens DE. New directions in endodontics. Interview by Mark J. Friedman. Compend Contin Educ Dent. 2002;23(8):742-4 746, 748

Whaites E. Chapter 10. Periapical radiography. In: Essentials of Dental Radiology and Radiography. 4th ed. Philadelphia, PA, USA: Churchill Livingston Elsevier; 2007.

Wolcott J, Ishley D, Kennedy W, Johnson S, Minnich S, Meyers J. A 5 year clinical investigation of second mesiobuccal canals in endodontically treated and retreated maxillary molars. J Endod. 2005;31:262-4.

Zou X, Liu D, Yue L, Wu M. The ability of cone-beam computerized tomography to detect vertical root fractures in endodontically treated and non endodontically treated teeth: a report of 3 cases. Oral Surg Oral Med Oral Pathol Oral Radiol Endodontic. 2011;111(6):797-801.

\section{Publisher's Note}

Springer Nature remains neutral with regard to jurisdictional claims in published maps and institutional affiliations.

\section{Submit your manuscript to a SpringerOpen ${ }^{\circ}$ journal and benefit from:}

- Convenient online submission

- Rigorous peer review

- Open access: articles freely available online

- High visibility within the field

- Retaining the copyright to your article

Submit your next manuscript at $\boldsymbol{\nabla}$ springeropen.com 